\title{
A STUDY ON FSW PARAMETERS OF JOINING DISSIMILAR METALS - AL AND FE
}

\author{
Kolluru Yugandhar, P S Balaji, P.Chandu, R Vamsi Prasanna, M N Magesh, T G Loganathan \\ R.M.K.College of Engineering and Technology, \\ Department of Mechanical Engineering, Tamilnadu, India \\ loganathan@rmkcet.ac.in
}

\begin{abstract}
The materials with similar and dissimilar qualities are joined effectively in their solid-state by Friction Stir Welding (FSW). FSW eliminates the conventional problems and produces crack-free and completely solidified joints. In recent years the commercialization of FSW is focused on metals like Fe and Al-based alloys. However, to commercializesuch a process numerous research studies are required to characterize and establish process windows. FSW process is suitable for joining the different materials having different mechanical and chemical properties and for different material structures. In general, aerospace applications require hybrid metal joins to offer high strength high ductile properties by joining varied metal alloys. FSW is the feasible way to join such metals to get high properties. This review mainly provides the feasibility ofthe FSW technique to join the different materials/alloys.
\end{abstract}

\section{Key Words: FSW, Aluminium, Steel, Process parameters, tensile strength.}

\section{Introduction}

Friction Stir welding and its types were invented by The Welding Institute (TWI), in 1991 with an objective to join varied metal combinations like $\mathrm{Al}$, Steel, $\mathrm{Cu}, \mathrm{Mg}$, and $\mathrm{Ti}$ in the solid-state [1]. In FSW, the materials to be joint are softened by the frictional heat generated by the stirring action of the simple tool with combined tool rotational and tool traverse movements. The presence of solidification, porosity defects,and intermetallic compounds in the fusion welding of Al has been overcome by FSW with an additional ability to join with hard metals like Fe. The merits of FSW include less energy requirement, less pollution, low cost, and easy procedure.

Unlike Shielded Metal Arc Welding (SMAW), the need for skilled operators and costly equipment are replaced with common fixtures, tool rotating spindle, and semi-skilled person to perform metal joining in FSW.

However, combinationsof alloys have important applications in the aerospace, automobile, and shipbuilding industries. In all these applications it becomes necessary to get the higher performance of the welded joints. The main advantage of using dissimilar materials in welding structures is to reap the advantages of the combined properties of both materials.

The factors which mainly influence the welding quality in FSW(Fig.1) are as follows:

- Material behavior on joining.

- Ability to form intermetallic compounds.

- Thermal conductivity

- Material positioning in advance and retreating side.

- Tool terminology: Shoulder pin, angle

- Welding parameters: rpm, traverse speed.

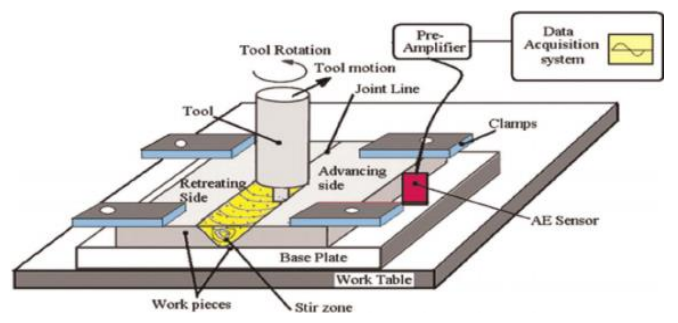

Fig. 1 Schematic diagram of FSW Setup 


\section{Principle of operation}

Friction stir welding (FSW) is a solidstate joining process that uses a non-consumable rotating and traversing tool to the faces of the workpieces without melting them. The profiled pin called probe at the front end of the rotating tool performs the metal joining. The diameter and length of the probe arekept smaller than the respective dimensions of the shoulder. The probe of the rotating tool is fed into the joining faces of the clamped workpieces until the shoulder touches the surface of the workpieces. Although the probe is shorter it should be less than the weld plate thickness to prevent tearing of the join during tool movement. After the start of the welding, a short dwell time is given to enable the metal to soften, and then the tool is moved forward at a constant speed along the joint line [2].

As mentioned earlier, the frictional heat generated between the tool and the workpiece softens the joint region near the FSW tool. The softening of the metal leads to plasticizing the region in the direction of leading to the rear with high force helps in forged consolidation of the weld. The process of metal softening, plasticizing, and consolidation is continuous along the path of tooltraverse resulting in dynamic recrystallization ofsolid-state deformation of the metal.

On the tool traverse along the joint line, the probe mixes the plasticized material mechanically,

and compresses the hot and softened metal by the mechanical pressure to form a solid-state joint. This type of jointishighly preferred to join dissimilar materials aiming at structures with high strength. Thus, FSW is predominately used in the joining of $\mathrm{Al}, \mathrm{Cu}, \mathrm{Ti}$ alloys, mild steel, stainless steel, and magnesium alloys[3]. More recently, it was successfully used in the joining of polymers. In addition, the joining of dissimilar metals, such as aluminium to magnesium alloys, has been recently achieved by FSW.

\section{FSW Process parameters}

The commonly considered process parameters in FSW are listed below and discussed in the following section. Fig. 2 illustrates the schematic of the terms involved in FSW
1. Tool design and geometry
2. Welding / transverse speed
3. Plunge depth
4. Axial tool's Plunge force
5. Tool tilt angle
6. Dwell time.

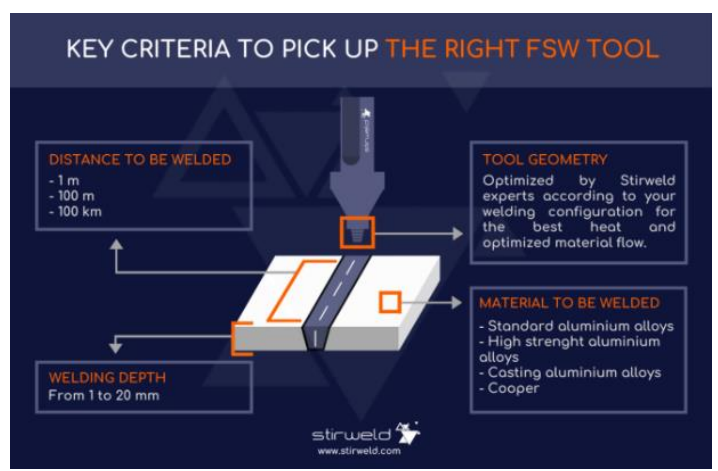

Fig. 2 FSW tool terminology

\subsection{Tool design and geometry}

The design of the toolis a critical factor, as a good tool can improve both the quality of the weld and the maximal possible welding speed.Fig. 3, depicts the criterion necessarily considered in the selection of the FSW tool. The FSW tool should have high strength, toughness, hot wear resistance, good oxidation resistance, and low thermal conductivity to minimize heat loss and thermal damage to the machinery[4].

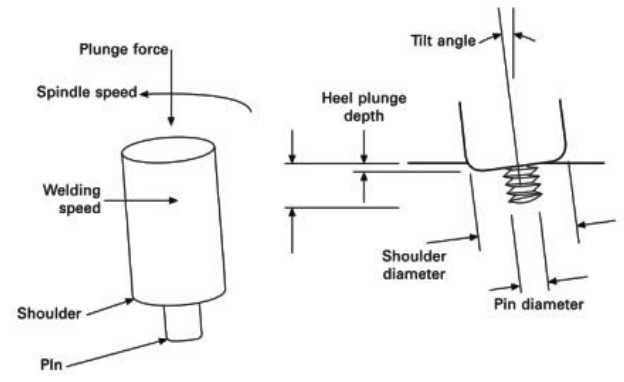

Fig. 3. FSW tool criterion

The design of the tool is a critical factor, a good tool can improve both the quality of the weld and maximize the possible welding speed. Fig. 4 illustrates the possible tool geometry tried in FSW process[5].

Hot-worked tool steel such as AISI H13 has proven to be good for welding $\mathrm{Al}$ alloys in the 
thickness range from 0.5 to $50 \mathrm{~mm}$, whereas advanced tool materials are necessary for highly demanding applications such as highly abrasive metal matrix composites or higher-melting-point materials such as steel or titanium.

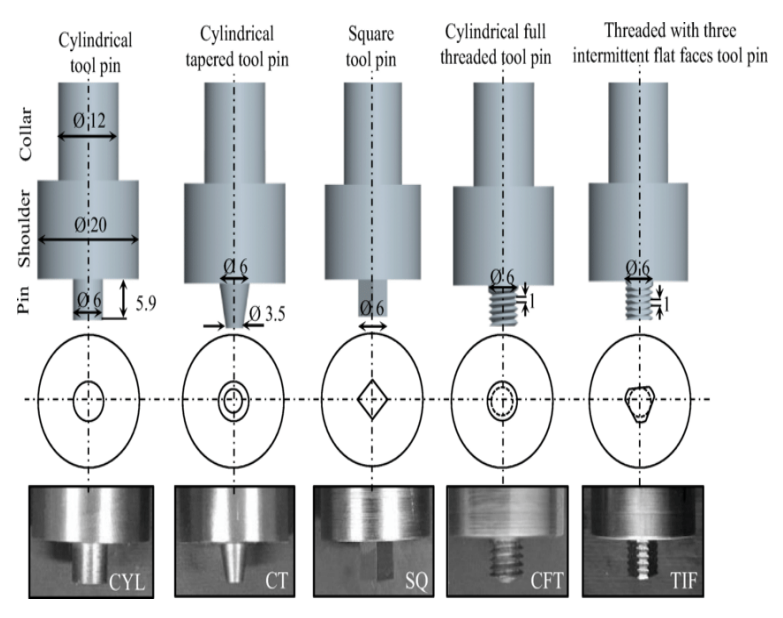

Fig. 4 FSW tool geometry

\subsection{Welding speed or Traverse speed}

Welding speed, also called as tool traverse speed, is one of the crucial parameters of FSW( Fig.2).The process temperature attained during welding increases with decreasing weld travel speed as well as increasing rotation speed of the tool. Thus, there exists an inverse relation between weld speed and heat generatedis sufficient to increase rotation speed to increase weld temperature [6].

High welding speed has been proved to increase stressand wear on the tool. These can lead to an increased incidence of defects and require repairs or deliveryof scrapped components. Hence, the optimum welding speed is therefore not normally the fastest possiblespeed.

\subsection{Tool rotational speed}

Another process parameter of FSW is the rotation speed of the tool. It is directly related to the increase in processing temperature. The increase of the rotation speed results in a higher processing speed and need higher cooling rates.

\subsection{Plunge depth and force}

Heel plunge depth corresponds to the distance the heel extends into the weld metal (Fig.2). The axial force is the force applied to the workpiece along the axis of tool rotation. The downward force applied ensures the continuous contact between the shoulder and the workpiece surface to generate heat from the friction of these two surfaces. This force is necessary to ensure a constant heel plunge depth and a good weld. The axial force is directly related to the plunge depth, the deeper the heel plunge depth the higher will be the axial force.

\subsection{Tool tilt angle}

Tilt angle is the angle between the centerline (Fig.2) of the tool and a line perpendicular to the surface of the workpiece. A featureless shoulder usually employs a tilt angle, leaning backward in respect of the welding path, which means there is more room in front of the tool, and the back of the tool does the forging of material behind the pin.

\subsection{Dwell time}

The time period during which the stationarilyrotating tools preheats the material to achieve sufficient temperature ahead of the tool is called Dwell time. This is also equivalent tomention as the plunge periodof the tool into the workpiece.

\section{FSW of dissimilar metals alloys}

The joining of dissimilar metals by FSW is a growing area of concern because of the limitations. The common setbacks that need to be addressed in FSW of joining dissimilar metals are following:

\subsection{Heat generation and temperature distribution}

The analytical estimation of heat generation at the tool-workpiece interface in conventional welding is relatively easier because of the presence of only one type of material in contact with the tool. However, things become quite complicated when it comes to heat generation and temperature distribution in dissimilar FSW. Two different materials, have different thermal properties, coefficient of friction, and softening characteristics all these affect heat generation and the temperature distribution in the workpieces. In dissimilar material joining, the presence of changing thermal field induces a narrow temperature gradient in low thermal diffusivity material that would result in a lack of bonding and defects at the weld root.

\subsection{Formation of intermetallic compounds}

In conventional fusion welding of dissimilar metals, the formation of the intermetallic compound leads to loss of joint strength and integrity. The 
factors contributing to the formation of intermetallic compounds are weld parameters and temperature. On having stringent control over the weld parameters, the formation of compounds can be minimized though it is not eliminated. Further, such formation in FSW is minimal which makes FSW joints with higher mechanical strength.

\subsection{MATERIAL FLOW IN WELDING ZONE}

The material flow during FSW is separated into two kinds of flow as given below.

- Material flow due to pin: layer by layer

- Material flow due to shoulder: material from retreating side(RS) is transferred through the shoulder surface at the top of the advancing side (AS)[7].

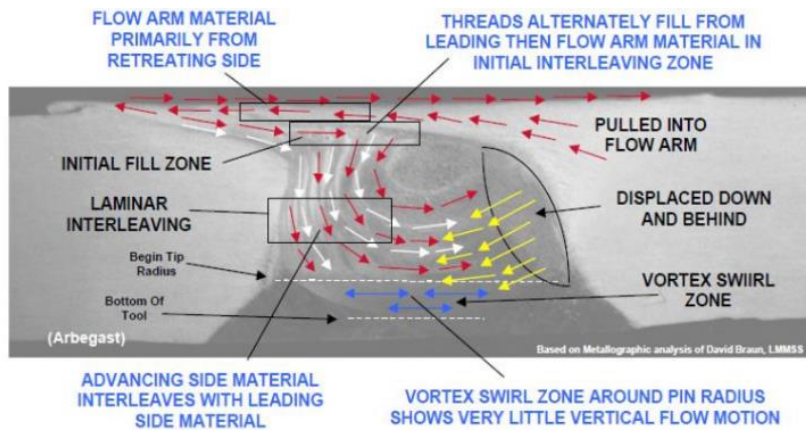

Fig. 5 Material Flow in FSW

Fig. 5 is the representation of material flow in FSW with the legend (arrow) explanation as follows:

- A part of the material is transferred from RS to AS (red arrows).

- A volume of material from the upper part of AS and down from the left area of the flowarm is deposited to the right part of the extrusion zone (at AS) and to the middle of the weld nugget (white arrows).

- Another volume of material of the extrusion zone at RS is shifted downwards and to the rear (yellow arrows).

- The down part of the weld nugget is composed of the vortex zone (blue arrows).

\subsection{Weld Zones in FSW}

Unlike another welding process, FSW has few additional zones in the weld as listed below:
- Initial deformation
- Extrusion
- $\quad$ Forging
- Cooldown

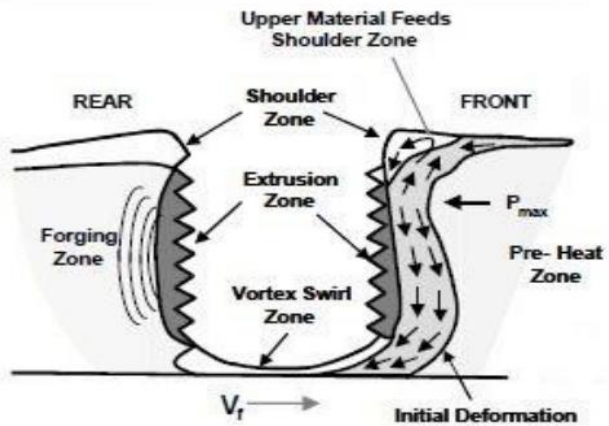

Fig. 6 Zones of FSW

$>$ The heat produced from the rotating motion of the tool preheats the area in front of the tool.

$>$ The rotational motion of the tool creates the initial deformation zone.

$>$ In this zone, the metal is forced upward into the shoulder and then down into the extrusion zone.

$>$ In the extrusion zone, the metal front is moved around the pin tool to the exitingwake of the weld in the cavity being vacated by the pin as it moves forward.

$>$ The back part of the shoulder passes over the metal that exits from theextrusion zone and forges it, ensuring the welding.

$>$ Then, the metal cools down.

5. Properties of FSW quality

There are various qualifying parameters to quantify welded joints. Most often they are the prerequisite for all types of weld joints. The weld quality parameters are classified as

\subsection{Mechanical properties}

The mechanical properties of the weld are crucial in arriving at the resultant weld strength. Some of the common mechanical properties that determine the weld quality are Tensile strength, Strength/weight ratio, Elastic modulus, Shear strength, Impact strength, percentage elongation,Wear, Corrosive behavior, fracture characteristics, Fatigue, etc.

- Pre-heat 


\subsection{Microstructural properties}

Every FSW process parameter considered during welding has a significant impact on the final microstructure[5]. Microstructural evaluation reveals the changes happening within the weld zone and the formation of intermetallic compounds. Some of them are Scanning Electron Microscopy (SEM), TEM, Dispersive X-ray analysis techniques which include EDX \& XRD, EBSD, Optical microscopy etc[8].

\subsection{Thermal properties}

In addition to the mechanical and microstructural properties of welded joints, the thermal behavior of the weld joint is yet another property influenced by the FSW process parameters. In the case of dissimilar alloys, the role of temperature is crucial as it determines the formation and thickness of intermetallic compounds. Some of the common thermal analysis methods like Thermogravimetric analysis, Differential scanning calorimetry, Thermomechanical analysis, etc. can be used to understand the behavior of the materials /metals.

\section{FRICTION STIR WELDING OF ALUMINIUM AND STEEL}

\subsection{Materials}

The materials considered for comparing the FSW weld properties are plates of 2-mm-thick

- $\quad$ SS400 mild steel (hereafter, Fe) and

- $\mathrm{A} 5083$ (Al-0.5 Mg-0.5 Mn wt-\%) aluminum alloy (hereafter, $\mathrm{Al}$ ).

The material properties considered in this article are the ultimate tensile strength of the A5083 and SS400 which are $275 \mathrm{MPa}$ and $455 \mathrm{MPa}$ respectively. The shape and size of the material taken for the weld are rectangles with size $140 \times 40 \times 2$ ( all dimensions are in $\mathrm{mm})$ [9].

\subsection{Method}

The chosen material was cleaned with fine-grit emery paper to remove dust and then mounted on the jig with the weld face of length $140 \mathrm{~mm}$ facing one another and clamped firmly. The tool steel (SKH57) was used to make FSW tool with a $15 \mathrm{~mm}$ diameter shoulder and unthreaded pin of $1.9 \mathrm{~mm}$ long and 2 mm diameter, as shown in Fig. 7.
The rotating speed of the FSW tool was in the range $100-1250 \mathrm{rpm}$ with $25 \mathrm{~mm} / \mathrm{min}$ transverse speed[10]. The Al plate was located on the retreating side as shown in Fig. 7. After the rotating pin was inserted into the $\mathrm{Al}$ plate, the pin was thrust toward the Fe faying surface by the distances of $-0.2 \mathrm{~mm}$ to $2 \mathrm{~mm}$ (zero is at the position where the pin side face is located just at the Fe faying surface, and the offset is defined as shown in Fig. 7b.

Studies were also performed with weaving pattern assigned to tool path for better weld quality [11-18]

\subsection{Testing of Weld Specimens}

1. Tensile test was employed to estimate the tensile strength of the joints and the fracture path. The tensile test specimens perpendicular to the weld interface were machined from the welds. While machining, it was made to have welded area at the center of the tensile specimen.

2. Metallographic samples were produced from the welds and etched with only an etchant of $3 \%$. Etched samples were examined using an optical microscope and scanning electron microscope (SEM) with X-ray and energydispersive spectroscopy (EDS).

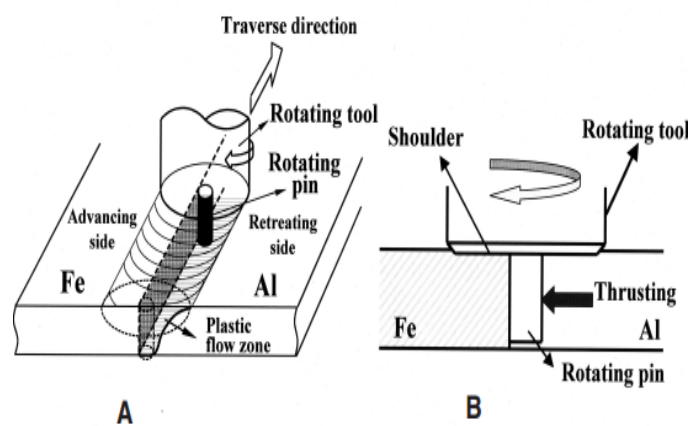

Fig. 7. $\mathrm{FSW}$ of $\mathrm{Fe}$ and $\mathrm{Al}$

A bird's-eye view of the methodand a view of the cross-section perpendicular to a weld interfaceare depicted in Fig. 7. While welding by FSW, the rotating tool pin is pushed toward the faying surface of the hard material - Steel which removes the oxide film from the material surface by the rubbing action of the tool. 
Aluminum, which is in a fluid-like plastic state due to the heat generated by the friction of the rotating tool shoulder, adheres to the activated faying surface of the steel so that joining between steel and aluminum is achieved.In this process, the tool wear is minimaldue to the fact that the rotating pin is plunged into the softer aluminum and does not come in contact with the steel.

Welding by FSW is ordinarily completed through stirring by a rotating pin inserted around the center of the weld interface of butted base plates. A preliminary experiment proved that when the rotating pin was inserted around the center of the weld interface between the steel plate and the aluminum alloy plate, welding could not be achieved because of excessive wear of the rotating pin in a short duration. The wear caused insufficient stirring between the aluminum alloy and the steel.

\subsection{Results and discussion}

- Effect of Pin Rotation Speed on Joint Tensile Strength

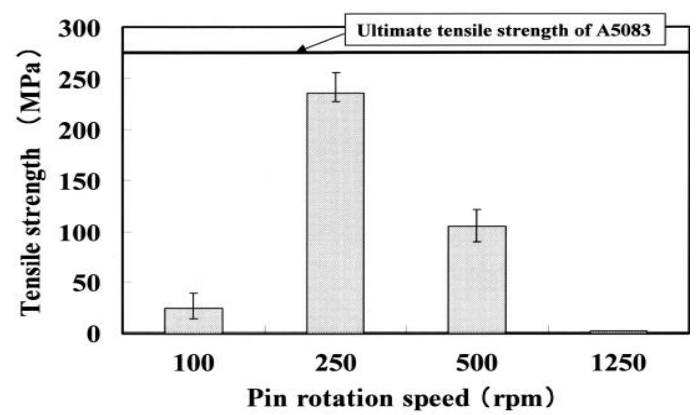

Fig. 8 Tensile strength Vs Pin rotation speed in FSW

The rotation speed of the pin is significant in heat generation. At $100 \mathrm{rpm}$ the heat generation was minimal and unable to plasticize even soft metal Al. Hence, there was an incomplete fusion between $\mathrm{Fe}$ and $\mathrm{Al}$, so the tensile strength of these specimens was low. In contrast to the above and on rising pin rpm to 250 , complete mixing ofmetal is possible offering maximum tensile strength of $24 \mathrm{MPa}$ which is $86 \%$ of the base metal.

With the further rise in pin rpm to 500, the surface morphology of the weld was similar to that of $250 \mathrm{rpm}$; however, the joint strength was not much appreciable than at $250 \mathrm{rpm}$. At $1250 \mathrm{rpm}$, the joint failed much earlier than other rotational speeds attributed to the effect of weld zone oxidation and incomplete weld.

The fracture surface appeared to be heavily oxidized and appeared to be burned. Thus the above results show to highlight the optimum tool $\mathrm{rpm}$ for this combination of $\mathrm{Al}-\mathrm{Fe}$ joint by $\mathrm{FSW}$ is $250 \mathrm{rpm}$.

\section{- The Effect of Pin Offset on Joint Tensile Strength}

The effect of pin offset on the tensile strength of aFSW joint of Al- Fe metal is shown in Fig. 9. The experimental condition considered for the evaluation are pin rotation speed $-250 \mathrm{rpm}$ and transverse velocity $-25 \mathrm{~mm} / \mathrm{min}$. The pin face contact wrt line of joint may give positive or negative offset. For positive offset, not more than $0.2 \mathrm{~mm}$ exhibited higher tensile strength and any variation from $0.2 \mathrm{~mm}$ either positive or negative there exist strength degradation.

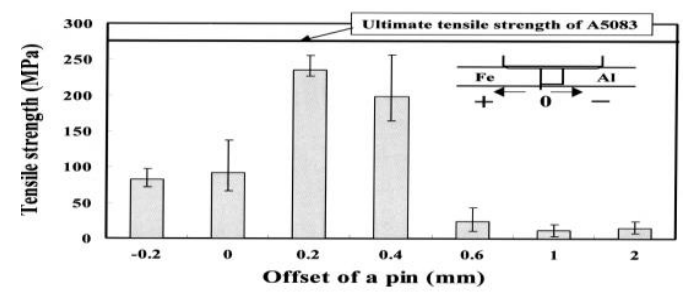

Fig. 9 Tensile Strength Vs Pin Offset in FSW

- The Effect of Rotating Pin Diameter on Joint Strength

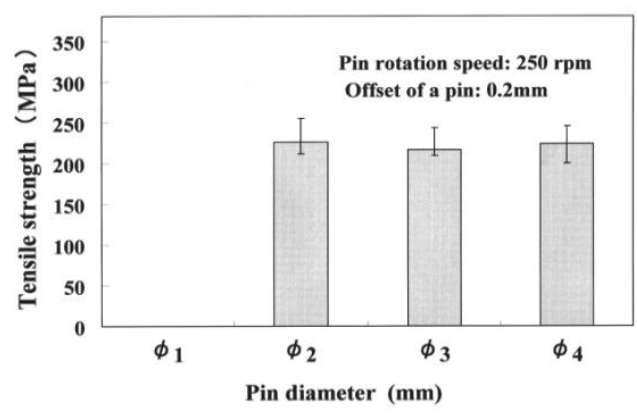

Fig. 10 Tensile Strength Vs Pin dia in FSW

Most often, a rotating pin of a diameter of 2-mmwas used to make a joint. In this section, the effects of various pin diameters on joint strength are examined. Joints were made using pins of 1,3 , and $4 \mathrm{~mm}$ 
diameter under the welding conditions of $0.2-\mathrm{mm}$ pin offset, 250-rpm pin rotation speed, and $25-\mathrm{mm} / \mathrm{min}$ welding speed. A pin of $1 \mathrm{~mm}$ diameter wore out in such a short duration that a sound joint could not be produced. The tensile strength of the joint made with a pin of 3 or $4 \mathrm{~mm}$ diameter was similar to those made using a 2-mm-diameter pin. It appears that rotating pin diameter has little effect on joint strength( Fig. 10).

\section{- The Effect of direction ofpin rotation}

The effect of pin rotation direction on joint performance was also examined by many researchers. In this work, the pin rotation direction was reversed in comparison to other FSW. On having counterclockwise pin rotation direction, the position of $\mathrm{Al}$ was on the advancing side of the joint.

The weld parameters taken in this work are $2 \mathrm{~mm}$ pin diameter, $250 \mathrm{rpm}$ pin rotation speed and 25 $\mathrm{mm} /$ minwelding. It appears from Fig. $11 \mathrm{a}$ and $\mathrm{b}$, that welding was successfully achieved. However, welding was restricted to the top surface and showed little bonding within the plate.
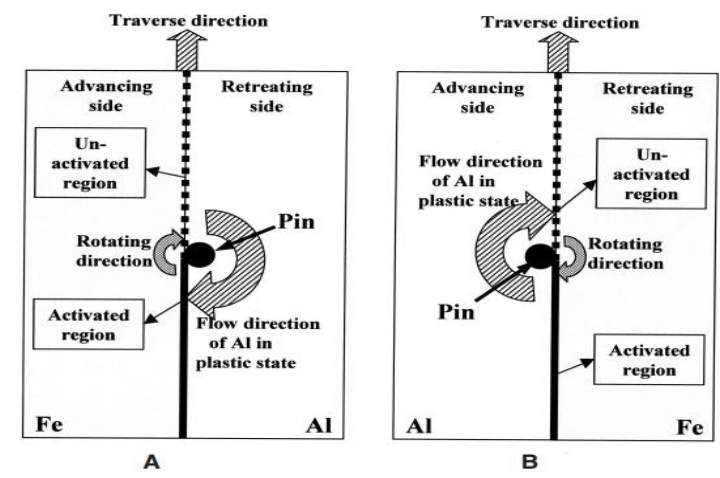

Fig. 11 Rotation direction of pin in FSW

\section{CONCLUSION:}

In this study, the effects of pin rotation speed and pin offset toward the steel faying surface on the tensile strength of a joint were reviewed and thefollowing results arearrived.

$>$ An optimum rotation speed for the pin would exist to make a sound joint. At lower tool rpm, heat generation is high that leading to pin wear however, oxidation is expected at a higher rotation speed.
$>$ Rotating pin position helps to activate the faying surface of the metal and enables a joint to be produced.

$>$ Minimum pin offset toward hard material results in reduced scattering in soft alloy with minimal voids and enhanced joint tensile strength.

$>$ Higher weld zone temperature results in Intermetallic compounds which deteriorates the weld strength.

$>$ A minimum pin size was required to produce a weld. Pins with very small diameters $(\leq 1 \mathrm{~mm})$ could not support welding and Pins with $2 \mathrm{~mm}$ has the same tensile strength. This opens up the need of a parametric study of the Pin size effect on the mechanical strength of FSW joints.

$>$ Sound weld joins are also controlled by effective selection of pin rotation direction.

\section{REFERENCES:}

[1] M. Kemal KÜLEKCİ, U. Eşme, C. Boğa, and S. YağKeçeleri San ve Tic AŞ, "Multi Response Optimization of Friction Stir Spot Welding Process Using Taguchi Based Grey Relational Analysis," 2021.

A. Heidarzadehet al., "Friction stir welding/processing of metals and alloys: A comprehensive review on microstructural evolution," Progress in Materials Science. Elsevier Ltd, $2020 . \quad$ doi: 10.1016/j.pmatsci.2020.100752.

[3] B. T. Ogunsemi, T. E. Abioye, T. I. Ogedengbe, and H. Zuhailawati, "A review of various improvement strategies for joint quality of AA 6061-T6 friction stir weldments," Journal of Materials Research and Technology, vol. 11. Elsevier EditoraLtda, pp. 1061-1089, 2021. doi: 10.1016/j.jmrt.2021.01.070.

[4] A. Kumar and R. S. S. Jadoun, "FRICTION STIR WELDING OF DISSIMILAR MATERIALS/ALLOYS: A REVIEW," 2014. [Online]. Available: www.ijmerr.com

[5] E. N. Ryl'kov, F. Y. Isupov, A. A. Naumov, O. v. Panchenko, and A. I. Shamshurin, "Microstructure and Mechanical Properties of Dissimilar $\mathrm{Al}-\mathrm{Cu}$ Joints Formed by Friction Stir Welding," Metal Science and Heat Treatment, vol. 60, no. 11-12, pp. 734-738, 


\section{International Journal of Trendy Research in Engineering and Technology Volume 6 Issue 1 February 2022 ISSN NO 2582-0958}

Mar. 2019, doi: 10.1007/s11041-019-003488.

[6] N. Sharma, M. Atif Wahid, Z. A. Khan, A. N. Siddiquee, and S. Singh, "Effect of Traverse Force and Temperature variation during FSW."

[7] J. Ansari, "Undergraduate Research on Friction Stir Welding of Copper-Aluminum Join."

[8] A. Mishra, "Surface quality analysis of friction stir welded joints by using fourier transformation and local binary patterns algorithms," Soldagem e Inspecao, vol. 25, pp. $1-11, \quad 2020$, doi: 10.1590/01049224/SI25.27.

[9] M. Yunus and M. S. Alsoufi, "Mathematical Modelling of a Friction Stir Welding Process to Predict the Joint Strength of Two Dissimilar Aluminium Alloys Using Experimental Data and Genetic Programming," Modelling and Simulation in Engineering, vol. 2018, 2018, doi: $10.1155 / 2018 / 4183816$.

[10] C. Vimalraj and P. Kah, "Experimental review on friction stir welding of aluminium alloys with nanoparticles," Metals, vol. 11, no. 3. MDPI AG, pp. 1-28, Mar. 01, 2021. doi: 10.3390/met11030390.

[11] Elangovan.K,

Balasubramanian,Babu.S,Balasubramanian $\mathrm{M}$ “Optimising friction stir welding parameters to maximise tensile strength of AA6061 aluminium alloy joints", International Journal of Manufacturing Research, 3, 3, 2008, pp.321-334.

[12], Elangovan.K, Balasubramanian.V and Babu.S, Balasubramanian $\mathrm{M}$ "Optimizing friction stir welding parameters to maximize tensile strength of AA2219 aluminum alloy joints" Metals and Materials International, 2(15), 2009, pp.321-330.

[13] Jayabalakrishnan D, Balasubramanian M, Prabhu P, Tamilselvam M, An overview of the effect of process parameters, tool geometry and joint geometry in friction stir welding and friction stir processing, International journal of applied engineering research, 2015, 10(71), pp.448-455
[14]

Jayabalakrishnan S, Balasubramanian M,Eccentric-weave Friction Stir Welding between $\mathrm{Cu}$ and AA 6061-T6 with reinforced Graphene nanoparticles, Materials and Manufacturing Processes 33(3), 2018, pp.333-342

[15] JayabalakrishnanD,Balasubramanian M A Study on Friction Stir Welding on various Materials-A Review, International Journal of Engineering Technology Science and Research, 2017, 4(5), pp.247-253

[16] JayabalakrishnanD, Balasubramanian MFriction stir weave welding (FSWW) of AA6061 aluminium alloy with a novel tool path pattern, Australian Journal of Mechanical Engineering, 17(2), 2019, pp.133-144

[17] Jayabalakrishnan D, Balasubramanian M Friction Stir Welding of Dissimilar Butt Joints with Novel Joint Geometry, Acta Physica Polonica A, 2018, 133, pp. 94-100

Jayabalakrishnan D, Balasubramanian M Effect of Square Wave Tool Path Pattern on Mechanical and Microstructure Properties of Friction Stir Welded AA6061-Cu Dissimilar Alloys, Journal of the Chinese Society of Mechanical Engineers, Vol.40, No.6, pp 711 717, 2019. 